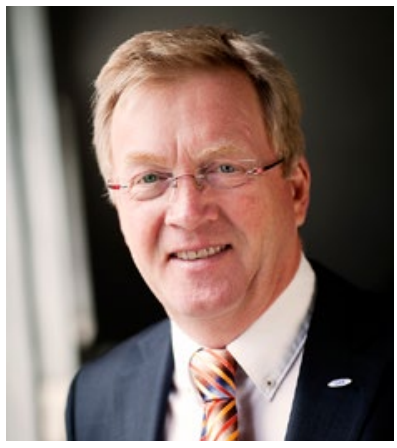

Andreas Westerfellhaus

Präsident Deutscher Pflegerat e. V.
Deutscher Pflegerat e.V.

Bundesarbeitsgemeinschaft

Pflege- und Hebammenwesen

In Kooperation mit

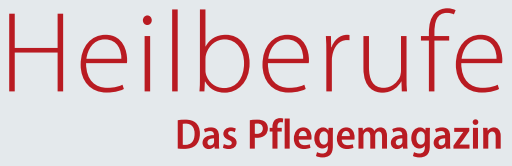

\title{
Editorial
}

\section{Pflege stärken mit starken Partnern}

W ir haben es in der Hand zu entscheiden, wie die Zukunft der Pflege und unsere Rolle darin aussieht. Dazu bedarf es starker Signale, einer starken Präsenz und vor allem Ihrer Mitwirkung. Lassen Sie uns auf dem Deutschen Pflegetag 2016 in Berlin gemeinsam zeigen, dass wir uns der großen Verantwortung bewusst sind, die wir für Millionen Pflegebedürftige, deren Angehörige und die Ausgestaltung und Weiterentwicklung unserer Profession tragen. Lassen Sie uns jedoch auch zeigen, dass wir Erwartungen haben ohne die eine gute Pflege nicht funktionieren kann.

Der dritte Deutsche Pflegetag wird im Jahr 2016 die Signale für eine starke Fortentwicklung der Pflege setzen. Er wird der Leuchtturm für die Zukunft unserer Branche sein. Er wird die Richtung vorgeben und dort, wo es nötig ist, sich als fester Orientierungspunkt erweisen. Das Motto des Deutschen Pflegetags „Pflege stärken mit starken Partnern“ haben wir unverändert gelassen. Denn nur gemeinsam sind wir stark. Wie in diesem Jahr lädt auch 2016 der geschichtsträchtige Flughafen Berlin-Tempelhof zum intensiven Dialog ein. Als Veranstaltungsort ist er ein Symbol für Begegnung, Gemeinschaft und Fürsorge.

Jetzt kommt es auf Sie an. Nehmen auch Sie aktiv teil, um die notwendigen zukunftsweisenden Entwicklungen für unsere Berufe auf den Weg zu bringen. Wir sehen uns in Berlin.

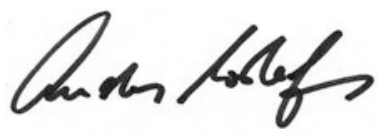

Andreas Westerfellhaus

Präsident Deutscher Pflegerat e. V. 